\title{
Effective Strategies for Language Instruction in Physical Education from the Perspective of Tacit Knowledge
}

\author{
Huanhuan Qi' ${ }^{1}$ Qi Zhang² \\ ${ }^{1}$ Trainee Affairs Division, Beijing Administration Institute, Beijing, China \\ ${ }^{2}$ College of PE and Sports, Beijing Normal University, Beijing, China \\ Email: qhh777@126.com
}

How to cite this paper: Qi, H. H., \& Zhang, Q. (2020). Effective Strategies for Language Instruction in Physical Education from the Perspective of Tacit Knowledge. Open Journal of Social Sciences, 8, 258-264. https://doi.org/10.4236/jss.2020.83024

Received: January 5, 2020

Accepted: March 17, 2020

Published: March 20, 2020

\begin{abstract}
In physical education, teachers often have difficulties in transmitting tacit knowledge contained in sports skill to students through language instruction. This article draws the following conclusions through literature analysis, logical reasoning, and practical experience summary: 1) Sports skill is practical, and it belongs to knowing how; 2) Sports skill is also tacit, and embodiment is the root of its tacit nature. The explicitness of sports skill is limited, and there are many ways of physical action and perception that are difficult for us to express accurately in language. 3) When the teacher's language instruction points to the body perception experience and specific way of doing, it can be more effectively transmit tacit knowledge, help students improve their physical actions and thereby creatively acquire sports skills. 4) Effective strategies for language instruction in physical education include: verb or adverb plus body parts, directions or spatial locations, action verb, metaphors and analogies, changes in intonation or specific stress, repeated words, onomatopoeia.
\end{abstract}

\section{Keywords}

Sports Skill, Knowing How, Tacit Knowledge, Physical Education, Language Instruction

\section{Introduction}

Sports skill can be perceived as the embodied tacit knowledge (Jakubowska, 2017). It is inside the body of the athlete, and it appears and disappears with the appearance of the exercise scene (Zhang, 2012). An athlete can only express his sports skill with language to a certain extent (Nyberg, 2015), and this language expression is insufficient (Qi \& Zhang, 2016). The difficulty of transmitting 
practical, embodied knowledge through language has also been emphasized in studies concerning sports skill teaching (Samudra, 2008). The author also found in the practice of physical education that students first learn by observing and imitating action demonstrations (Qi \& Zhang, 2019), however, they will have various wrong actions. At this time, teachers use language to guide students to continuously improve their movements, which is an essential teaching session. However, it is not an easy task for teachers to transmit tacit knowledge contained in sports skill to students through language instruction to help students improve their movements. So why is this happening (what is the reason), and how can teachers' language instruction transmit tacit knowledge more effectively?

This article will explore the practical and tacit natures of sports skill from the perspective of epistemology, analyze the reasons for the limitations of language instruction in physical education, and then combine the author's teaching experience and the results of related research to summarize the effective strategies of teachers' language instruction. It is hoped that these discussions will enable teachers to recognize the essential natures of sports skill, learn to use these effective strategies for language instruction to solve the confusion of tacit knowledge transmit, and improve teaching efficiency.

\section{Sports Skill Is Practical, And It Belongs to Knowing How}

In contemporary epistemology, Ryle proposed the distinction between knowing how and knowing that, which posed a great challenge to the "the intellectualist legend" since Descartes. He believes that knowing how refers to the practical ability of "knowing how to do something", which is a kind of knowledge reflected in the activities or actions of "doing"; knowing that means "knowing a certain fact" and is a kind of propositional knowledge (Ryle, 1946). Ryle made groundbreaking research on knowing how, not only affirmed knowing how is an independent type of knowledge, but also demonstrated the priority of knowing how over knowing that (Ryle, 1992). Rationalism believes that there is no kind of difference between knowing how and knowing that. Knowing how is a form of knowing that, and it dependents on knowing that. Anti-intellectualism opposes to seeing knowing how as knowing that, claiming there is a kind of difference between the two ( $\mathrm{Yu}, 2010)$. Although later philosophers have a lot of controversy about how to understand knowing how, on the whole, most philosophers lean in the anti-intellectualist direction and think that these are two distinct and different forms of knowledge.

In recent years, some researchers have made a distinction between the cognitive and practical dimensions of knowing how from the perspective of epistemology. Cheng-hung Tsai constructed an epistemological framework of knowing how, and proposed the concepts of "knowing-how" (where "P" means "proposition") and "knowing-how A" (where "A" refers to "ability") (Tsai, 2011). This epistemological distinction shows that people's understanding and grasp of "how to do something" includes two aspects: on the one hand, the 
theoretical understanding of "how to do" can form knowing-howp; on the other

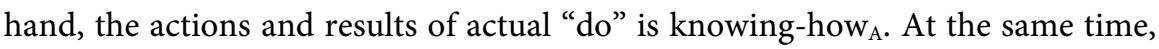
Gascoigne and Thornton distinguished between "theoretical knowledge-how" and "practical knowledge-how" (Gascoigne \& Thornton, 2013). They believe that "theoretical knowledge-how" means that a person theoretically knows how to ride a bicycle, play tennis, or play a musical instrument. People can obtain them from manuals, courses or videos, but this knowledge does not automatically translate into "practical knowledge-how", that is, being able to ride a bicycle, play tennis, etc. For tennis, learners need a lot of practice and understand the feedback from teachers in order to gain "practical knowledge-how". This article considers that Cheng-hung Tsai's distinction between "knowing-how ${ }_{\mathrm{P}}$ " and "knowing-how ${ }_{\mathrm{A}}$ " is similar to the distinction between Gascoigne and Thornton's "theoretical knowledge-how" and "practical knowledge-how". The former refers to the cognitive dimension of knowing how, and the latter refers to the practical dimension of knowing how.

Sports skill is practical, and it belongs to what Ryle calls knowing how. But knowing how in sports is not limited to sports skill, it also includes knowledge about cognition and grasp of sports situations (Breivik, 2104). So, to be precise, sports skill is the practical dimension of knowing how, which can only be demonstrated through the actions of athletes; and concepts, propositions, steps, methods, rules, beliefs, judgments, strategies, etc. related to sports skill actions, which belong to the theoretical dimension of knowing how. Teacher's language instruction in physical education is the theoretical dimension of knowing how, which can guide and inspire students through physical exercises to form the practical dimension of knowing how, that is, to acquire sports skill.

\section{The Tacit Nature of Sports Skill and Its Roots}

Polanyi divides human knowledge into two types: explicit knowledge and tacit knowledge (Polanyi, 1959). The former refers to knowledge that can be expressed in words and symbols. The latter refers to the knowledge we know but cannot tell, like the knowledge we have in doing something. Sports skill is a type of body knowledge (Kaneko, 2005), which is highly dependent on physical perception and belongs to tacit knowledge (Jia et al., 2009). Usually, when a sportsman is asked how to perform well, he may mention some action methods and skills derived from experience, but his sports skill cannot be fully speaking by this kind of language about action. For example, when a basketball player is asked, "How did you do that?" He said, "I just watch the ball and move my position, feel an opportunity and seize it instantly." The "mystery" and "knowledge" of sports skill are reflected in the specific movement process. The athlete can always do much more than he can say.

The reason why sports skill can be possessed tacitly by humans is that our bodies have the ability to move pre-intentionally. In reality, our intention of movement will always be directly changed into movement. As long as our inten- 
tion of movement points to a certain goal, the body will incredibly approach this goal and automatically complete the whole process of movement (Liu, 2011). We can move the body without knowing exactly which muscles and nerves are functioning; we can use the body without paying attention to it; we don't need to consider the spatial position of the body, as long as the body can be reached directly and spontaneously intentional purpose. Therefore, in sports practice, although we already have some kind of sports skill, we cannot fully realize how the body's movements are performed, and it is impossible to fully speak about it.

In related research, Merleau-Ponty's concept of body schema and Polanyi's theory of tacit knowledge have revealed the root of tacit nature of sports skill from the generation mechanism of body knowledge. Merleau-Ponty put forward the concept of body schema, and considered that body schema is an unconscious internal body posture pattern or body experience structure, which plays a pre-intentional role in cognition (Merleau-Ponty, 2012). In sports learning, when students see the teacher's action demonstration, the body schema representation of their similar activities will be aroused, and they can imitate while watching. The body schema maintains the perceptual structure required for the exercise, and actively regulates the body posture and movement, so that the sports skill can be revealed tacitly. The intrinsic nature of sports skill acquisition is the development of body schema. The richer and more detailed body schema, the higher the level of sports skill. Polanyi's thought of "knowing by indwelling" (Polanyi, 2000) gives a deep insight into the fundamental epistemology status of the body. In the understanding of everything, the subsidiary awareness of our body is included. In sports learning, physical participation is at the core. The athlete knows how to exercise sports skill as a whole and how to perform the basic actions that make up these skills, but most of his body functions as subsidiary awareness (Polanyi, 1969), and part of the subsidiary awareness is at the level of subliminal consciousness (Polanyi, 1962). Therefore, the athlete cannot identify and tell exactly what these movements look like and how he does them.

In summary, sports skill has practical nature, and practical action is the basic expression of knowledge in sports skill (Johannessen, 2007); sports skill also has tacit nature, most of which are in the tacit dimension, and their explicitness is very limited. However, the explicitness of sports skill, such as the steps, methods, and experience of movement, can guide beginners to learn sports skill faster and take less detours.

\section{Effective Strategies for Language Instruction in Physical Education}

Because the explicitness of sports skill is limited, there are many ways of physical action and perception that we can't accurately express in language. Therefore, although teachers' language instruction in physical education can play a guiding role in students' to learning sports skill, such guidance is also limited. Teachers cannot express all knowledge of sports skill in words. They usually use both 
language and body to teach students. In addition to language instruction, they also demonstrate their sports skill through demonstrations, and sometimes even need to teach by hand. Students can't learn sports skill just by reading exercise manuals. In addition to observing and imitating the teacher's demonstration, understanding the teacher's language instruction, they also need long-term practice and careful consideration to acquire a certain sports skill.

Although the guidance of teachers' language in physical education is limited to students, based on my teaching experience and related research findings, the author finds that when teachers' language instruction points to physical perception and specific way of doing, they can more effectively transmit tacit knowledge, help students perform physical actions, and creatively acquire sports skill. Table 1 shows effective strategies for language instruction in physical education.

The reason these language instruction strategies in Table 1 are effective is that they allow students to know exactly what to do and how to do it. By following such instructions, students can try to adjust their actions and recognize that body perception, and they can improve their movements in the right direction. Among them, the use of metaphors and analogies deserves special emphasis. Metaphors and analogies can vividly express the form of action, or subtly reveal the tacit knowledge inside the action. Students associate the form or inherent senses of that action, which help them to understand and find the correct body sense with the help of existing knowledge or similar physical experience. For example, the table tennis forehands arm movement is very similar to the shape of "salute". Students can transfer the existing physical experience and imitate the "salute" movement to quickly establish the basic movement structure. For another example, Taijiquan's action name "white crane spreads its wings", and the classic proverb "walking like a cat", Changquan boxing provberbs such as "moving like waves, falling like birds, turning like wheels, light like leaves, slow like eagles, fast like wind", which reveals the inner or overall sense of the action. Students follow these instructions in practice, it will help them recognize the correct sense of movement and gain internal physical experience.

\section{Conclusion}

From the perspective of epistemology, sports skill is practical, and it belongs to knowing how. Practical action is the basic expression of knowledge in sports skill. Sports skill is also tacit, and embodiment is the root of its tacit nature. The explicitness of sports skill is limited, and there are many ways of physical action and perception that are difficult for us to express accurately in language. When the teacher's language instruction points to the body perception experience and specific way of doing, it is often more effective in transmitting tacit knowledge to students to help them improve movements. Teachers can learn from the effective strategies summarized in this article and apply them in a flexible and practical way.

This article is only from the perspective of tacit understanding of sports skill, to talk about effective strategies for teachers to transmit tacit knowledge to 
Table 1. Effective strategies for language instruction in physical education.

\begin{tabular}{|c|c|c|}
\hline Effective strategies for language instruction & Function & Examples \\
\hline $\begin{array}{l}\text { verb or adverb plus body parts (Jakubowska, } \\
\text { 2017) }\end{array}$ & $\begin{array}{l}\text { pay attention to body parts and correct } \\
\text { movements }\end{array}$ & $\begin{array}{l}\text { bend your knees, stretch your arms, relax your } \\
\text { shoulders, fasten your forearms, and head up }\end{array}$ \\
\hline directions or spatial locations & know the direction and position of the action & $\begin{array}{l}\text { lower the center of gravity; swing from the } \\
\text { bottom right to the top left; step forward } 45 \\
\text { degrees to the left }\end{array}$ \\
\hline action verb & know the way to act & $\begin{array}{l}\text { "cut" the lower part of the ball forward to the } \\
\text { bottom; increase the jitter of the wrist; rub the } \\
\text { sides of the ball }\end{array}$ \\
\hline metaphors and analogies (Ma, 2008) & $\begin{array}{l}\text { inspire students to imagine movement patterns } \\
\text { or understand movement senses }\end{array}$ & $\begin{array}{l}\text { imagine yourself tall in gymnastic exercises to } \\
\text { inspire stretch and erect feeling; bow back like a } \\
\text { kitten }\end{array}$ \\
\hline changes in intonation or specific stress & $\begin{array}{l}\text { emphasize points of action, such as the role of } \\
\text { specific parts of the body, important timing, or } \\
\text { letting students notice mistakes }\end{array}$ & $\begin{array}{l}\text { "Wave your arms up!" "Slow down!" "Stop! See if } \\
\text { your center of gravity is on your left leg?" }\end{array}$ \\
\hline repeated words & $\begin{array}{l}\text { give feedback, adjust and enhance movement } \\
\text { details }\end{array}$ & "Yes, yes, hurry up" "Relax, relax" \\
\hline onomatopoeia & $\begin{array}{l}\text { describe the rhythm of movement or have } \\
\text { students remember the right voice }\end{array}$ & $\begin{array}{l}\text { the rhythm of high jump run, "da-da-da" the } \\
\text { sound of rubbing the ball, "ca-ca" }\end{array}$ \\
\hline
\end{tabular}

students through language instruction in physical education. In fact, the use of language instruction methods in physical education is more extensive than the coverage of this article. From a broader perspective, teachers can set up reasonable physical exercises for students, or can judge the reasons why students make wrong actions, which is the prerequisite for language instruction. In future research, the author will further explore more related issues from the perspective of tacit knowing theory.

\section{Acknowledgements}

Thanks to the special funds for basic scientific research business expenses of central universities for funding this research, and thanks to Professor Jianhua Zhang of Beijing Normal University for his guidance.

\section{Conflicts of Interest}

The authors declare no conflicts of interest regarding the publication of this paper.

\section{References}

Breivik, G. (2014). Sporting Knowledge and the Problem of Knowing How. Journal of the Philosophy of Sport, 41, 143-162. https://doi.org/10.1080/00948705.2014.911102

Gascoigne, N., \& Thornton, T. (2013). Tacit Knowledge. Durham, UK: Acumen.

Jakubowska, H. (2017). Skill Transmission, Sport and Tacit Knowledge: A Sociological Perspective. New York: Routledge. https://doi.org/10.4324/9781315267043 
Jia, Q., Li, B., \& Yang, J. (2009). Research on the Methods of Movement Guidance at the Beginning of Motor Skills' Formation: Centered for the Targeted Physical Exercise Skills. Journal of Sports and Science, 30, 77-79. (In Chinese)

Johannessen, K. S. (2007). Knowledge and Its Modes of Articulation. In Gilje, N., \& Grimen, H. (Eds.), Discursive Modernity (pp. 167-168). Oslo: Universitetsforlaget.

Kaneko, A. (2005). The Formation of Body Knowledge: Lecture Notes on Motion Analysis. Tokyo: Meiwa Publishing. (In Japanese)

Liu, S. (2011). Bodily Experience and Bodily Representation: Merleau-Ponty's Methodological Criticism on the Body Model of Classical Psychology. Studies in Philosophy of Science and Technology, 28, 51-55. (In Chinese)

Ma, L. (2008). Metaphors and Interpretations of Sports Technology Concepts: A Metaphorical Study of the Four Skill-Driven Performance Difficulty and Beauty Projects. Beijing: Beijing Sport University Press. (In Chinese)

Merleau-Ponty (2012) Perceptual Phenomenology. Beijing: The Commercial Press. (In Chinese)

Nyberg, G. (2015). Developing a "Somatic Velocimeter": The Practical Knowledge of Freeskiers. Qualitative Research in Sport, Exercise and Health, 7, 109-124. https://doi.org/10.1080/2159676X.2013.857709

Polanyi, M. (1959). The Study of Man. Chicago: The University of Chicago Press.

Polanyi, M. (1962). Personal Knowledge. London: Routledge.

Polanyi, M. (1969). Knowing and Being. London: Routledge,.

Polanyi, M. (2000). Science, Faith and Society. Nanjing: Nanjing University Press. (In Chinese)

Qi, H., \& Zhang, J. (2016). A Study of Tacitness and Tacit Knowing of Motor Skills. Journal of Shandong Institute of Physical Education, 32, 103-107. (In Chinese)

Qi, H., \& Zhang, J. (2019). Interpretation of Tacit Knowing Methods in the Process of Motor Skills Acquisition. Journal of Shandong Institute of Physical Education, 35, 105-110. (In Chinese)

Ryle, G. (1946). Knowing How and Knowing That. Proceedings of the Aristotelian Society, 46, 4-5. https://doi.org/10.1093/aristotelian/46.1.1

Ryle, G. (1992). The Concept of Mind. Beijing: The Commercial Press. (In Chinese)

Samudra, J. (2008). Memory in Our Body: Thick Participation and the Translation of Kinesthetic Experience. Journal of the American Ethnological Society, 35, 665-681. https://doi.org/10.1111/j.1548-1425.2008.00104.x

Tsai, C. (2011). The Metaepistemology of Knowing-How. Phenomenology and the Cognitive Sciences, 10, 541-556. https://doi.org/10.1007/s11097-011-9208-0

Yu, Z. (2010). On the Ability of Knowing How: Making out a Case for Ryle. Philosophical Studies, 70-78. (In Chinese)

Zhang, J. (2012). Theory of Sports Knowledge. Beijing: Beijing Sport University Press. (In Chinese) 